\title{
Plant reproductive strategies are not correlated with morphological or genetic diversity in specialized pollination interactions
}

Maureen Murua ( $\nabla$ maureen.murua@umayor.cl)

Universidad Mayor Facultad de Ciencias

Anahí Espíndola

University of Maryland

Fernanda Pérez

Pontifica Universidad Catolica de Chile

Research article

Keywords: Calceolaria, self-incompatibility, Chile, specialized pollination, floral morphology, plant reproduction

Posted Date: April 6th, 2020

DOI: https://doi.org/10.21203/rs.3.rs-20993/v1

License: (9) This work is licensed under a Creative Commons Attribution 4.0 International License. Read Full License 


\section{Abstract}

Bachground: One of the most common evolutionary transitions in angiosperms is the reproductive change from outcrossing to self-fertilization, which has occurred independently in many lineages. This transition has been associated with changes in floral biology, ecology and genetics, with selfing species experiencing reduced floral display and herkogamy, rapid plant growth, and increased inbreeding depression. Here, we aim to test whether self-compatibility was associated with a reduction in floral traits important to the attraction and interaction with pollinators, and a reduction in genetic diversity and inbreeding.

Results: Our self-incompatibility tests indicated that $50 \%$ of the species studied here are selfincompatible. In relation to floral traits, we found that self-incompatible species do not show a reduction in the size of their floral traits, but rather we found larger corolla, elaiophore area, and herkogamy in selfcompatible ones. The microsatellite analysis did not identify any significant decrease in the genetic diversity or increase in inbreeding levels in the self-compatible Calceolaria species. Conclusions: Despite our results go against our expectations, in the case of Calceolaria, their high dependence on only two genera of oil-bees put the species in a vulnerable position, probably facilitating the evolution of mechanisms of reproductive assurance in the absence of pollinators. As a result, the plants maintain their attraction traits while evolving an ability to self. In addition, we also did not detect a significant change in genetic diversity or inbreeding when different reproductive strategies are used. This suggests that selfing could be delayed, facilitating -when possible- the exchange of genes by cross-pollination first, and buffering the negative genetic effects of self-pollination.

\section{Background}

One of the most common evolutionary transitions in angiosperms is the reproductive change from outcrossing to self-fertilization, which has occurred independently in many lineages [1-3]. This transition has been associated with changes in floral biology, ecology and genetics, with selfing species experiencing reduced floral display and herkogamy, rapid plant growth, and increased inbreeding depression [4-5]. Resource allocation theory has frequently been invoked to explain these changes, stating that once the transition to selfing occurs, the energy used in building large flowers can be reallocated to other functions, such as ovule production [6-7]. However, this reallocation is also dependent on pollination mode (e.g., animal, wind), since if animal pollinators are needed for pollen transfer (i.e., selfing is not autonomous), some of the floral attraction features will be maintained [8]. Herkogamy has also been shown to be reduced in plants with higher abilities of selfing [9], and is explained by the fact that reducing the distance between the reproductive organs can increase the ability of the plant to self-pollinate in the absence of pollen carriers. Finally, the genetic structure of the species is also expected to vary in selfers vs. outcrossers. Indeed, the former are expected to display lower genetic diversity than the latter, at least at the population level [10]. Taken together, one can expect that the morphological and negative genetic consequences of selfing will be higher in plants where fertilization occurs automatically [11]. 
Pollination specialization is expected to promote greater precision in floral handling, improving reliable pollen removal and deposition, and leading to lower levels of pollen limitation and high levels of outcrossing [12]. However, in response to the variability of the pollinator environment, plant species with specialized pollination systems can sometimes evolve autonomous selfing [12-14], which can be early or delayed [15]. Among these two, the latter is considered more advantageous, because it does not decrease outcrossing potential. In such cases, it has been observed that floral traits involved in outcrossing are retained (e.g., large flowers, large number of flowers, floral cues, pollinator rewards, among others [8], and it has been proposed that the costs of maintaining them are outweighed by the genetic benefits of an eventual cross-pollination [8]. Even though changes in trait values have been studied many times, the genetic consequences of the transition from outcrossing to selfing in plants displaying specialized pollination are still little understood.

The nectarless oil-rewarding plant genus Calceolaria L. and the oil-bees genera Centris and Chalepogenus interact to form a fascinating specialized American plant-pollinator system. In this system, Calceolaria flowers harbor an oil-secreting gland (the elaiophore), from which the oil-bees collect floral oils while passively pollinating the flowers [16-19]. Although the majority of the plants in the system are supposed to require insects for reproduction, investigations have shown that some species are also capable of autonomous selfing $[16,20]$. This has been hypothesized to evolve in response to the lack or unreliability of the pollination environment [16]. However, the extent of the transition between strictly outcrossing to selfing, and its morphological and genetic consequences has never been tested in this group.

In the present work, we propose to test the idea of reduced floral attraction traits and genetic diversity in selfing species using manipulative pollination experiments and microsatellites on 14 Calceolaria species belonging to the subgenus Cheiloncos (Fig. 1A; Table 1). Specifically, we aim to address the following questions: a) what is the breeding system of the 14 studied species?, b) is there a reduction in the floral traits associated with pollinator attraction (i.e., corolla area, herkogamy, elaiophore area; Fig. 1B) in selfing vs. outcrossing species?, and c) do self-compatible species have lower genetic diversity than outcrossers? To do this, we first experimentally estimate levels of incompatibility from pollination crosses in greenhouse and field conditions, then measure three floral traits important to the plant-pollinator interaction, and finally estimate four genetic diversity parameters using data from nine polymorphic microsatellites. Our expectations are that self-compatible species will display reduced pollinator attraction traits and genetic diversity. 
Table 1

Breeding system classification, floral traits measurements and self-incompatibility indexes for the fourteen studies Calceolaria species. BS: breeding system, SI = self-incompatible, SC: self-compatible. Floral traits = CA: corolla area, $\mathrm{H}$ : herkogamy and EA: elaiophore area. ISI: self-incompatibility indexes. Values are given as mean \pm standard error. Species which were cross-pollinated in greenhouse conditions are denoted by asterisk.

\begin{tabular}{|llllll|}
\hline BS & Species & CA $\left(\mathrm{mm}^{2}\right)$ & $\mathbf{H}(\mathrm{mm})$ & GA $\left(\mathrm{mm}^{2}\right)$ & ISI \\
\hline SI & C. ascendens* & $124.34 \pm 2.31$ & $0.75 \pm 0.018$ & $5.75 \pm 0.17$ & 0.02 \\
\hline & C. dentata* & $100.75 \pm 1.89$ & $1.69 \pm 0.04$ & $7.86 \pm 0.09$ & 0.14 \\
\hline C. glandulosa* & $97.63 \pm 1.47$ & $1.19 \pm 0.03$ & $8.04 \pm 0.09$ & 0.09 \\
\hline C. filicaulis ssp. filicaulis & $100.10 \pm 3.45$ & $5.0 \pm 0.36$ & $24.13 \pm 1.10$ & 0.14 \\
\hline C. purpurea & $60.61 \pm 3.32$ & $0.85 \pm 0.04$ & $6.54 \pm 0.34$ & 0.01 \\
\hline C. polifolia & $65.76 \pm 3.78$ & $2.04 \pm 0.21$ & $6.17 \pm 0.40$ & 0.05 \\
\hline C. segetthi & $117.97 \pm 8.07$ & $0.91 \pm 0.08$ & $17.28 \pm 1.55$ & 0.13 \\
\hline Mean \pm SE & $95.33 \pm 3.47$ & $1.78 \pm 1.12$ & $10.83 \pm 0.54$ & 0.08 \\
\hline C. arachnoidea & $94.84 \pm 3.31$ & $8.0 \pm 0.48$ & $6.30 \pm 0.23$ & 0.22 \\
\hline C. corymbosa & $157.67 \pm 4.7$ & $0.98 \pm 0.03$ & $10.78 \pm 0.29$ & 0.21 \\
\hline C. lanigera & $206.91 \pm 17.96$ & $1.81 \pm 0.10$ & $21.54 \pm 1.12$ & 1 \\
\hline C. latifolia* & $239.28 \pm 27.05$ & $3.14 \pm 0.23$ & $21.22 \pm 2.32$ & 1 \\
\hline C. petioalaris & $54.79 \pm 1.75$ & $2.20 \pm 0.06$ & $6.36 \pm 0.16$ & 0.91 \\
\hline C. integrifolia & $147.87 \pm 8.84$ & $1.24 \pm 0.07$ & $8.85 \pm 0.55$ & 0.23 \\
\hline C. filicaulisssp. luxurians & $141.60 \pm 7.83$ & $0.38 \pm 0.03$ & $58.56 \pm 3.04$ & 0.61 \\
\hline Mean \pm SE & $148.99 \pm 10.15$ & $2.54 \pm 0.15$ & $19.09 \pm 1.11$ & 0.6 \\
\hline
\end{tabular}

\section{Results}

\section{Breeding systems}

Our results show that seven of the 14 Calceolaria species tested here are self-incompatible (SI) at the ISI threshold used here (Table 1). Specifically, $C$. purpurea and $C$. ascendens were the species with the lowest ISI index (0.01 and 0.02$)$, showing that the species are able to produce only a very small proportion of seeds by manual selfing. On the contrary, $C$. lanigera and $C$. latifolia were the species with the highest ISI index (ISI=1), with both species able to develop a high amount of seeds by manual self-pollination (Table 1). 


\section{ISI and morphological traits}

Our results indicated that there are significant differences in corolla area, herkogamy and elaiophore area between SC and SI groups, were the values of each trait are in average greater in SC than SI species (Fig. 2, Additional File 1, Tabla S1). Specifically, among SC species, $C$. latifolia displayed the largest corolla area, while $C$. filicaulis ssp. luxurians presented the largest elaiphore but the lowest herkogamy (Table 1). C. petiolaris exhibit the smallest corolla area and $C$. arachnoidea the largest herkogamy and the smaller elaiphore (Table 1). In the SI group, $C$. segetthi had the largest corolla area and $C$. filicaulis ssp. filicaulis showed the largest herkogamy and elaiophore area (Table 1). Finally, $C$. purpurea displayed the smallest corolla size, while $C$. ascendens was the species with the lowest herkogamy and elaiophore size (Table 1).

The Principal Component Analysis (PCA) showed that the two first axes explained $79.71 \%$ of the variance (PC1 explained $49.85 \%$ and PC2 $29.85 \%$ ), with the herkogamy being virtually completely correlated with PC2 (Fig. 3). The PC1 was significantly and positively correlated with corolla area (CA) and elaiphore area (EA), while the PC2 was significantly and positively correlated only with herkogamy $(H)$. In the same way, the loading factor $(L F)$ analysis revealed that $E A(L F=0.89)$ was the trait that better explains the variance of the first component (CA had a LF=0.45). The second component was virtually completely explained by $\mathrm{H}(\mathrm{LF}=0.99)$. Our PCA indicates that SC and SI clustering as different groups according to the size of their attraction and reproductive floral traits (Fig. 3). The SC group was formed by species with larger corolla and elaiophore areas (e.g., C. latifolia and C. lanigera) while the SI group was formed by those with smaller corolla size (e.g., C. purpurea and C. corymbosa). When PCA scores were used as variables in the GLM analysis, ISI values were significantly explained by floral morphology for both PC1 and PC2 (GLM PC1: Estimate $=-0.23, \mathrm{t}-$ value $=-14.11, P<0.001 ;$ GLM PC2: Estimate $=-0.08, \mathrm{t}$-value $=-5.7, P<0.001)$.

\section{Genetic diversity}

Eleven of the fifteen primers tested amplified in most of the plant samples, but only nine where polymorphic in all the study species (Additional File 1, Tabla S2). The values of genetic diversity in each species group (Table 2) were not significantly different (Kruskall-Wallis test, $N a: X^{2}=1.47, \mathrm{DF}=1, P=0.23$; Ho: $X^{2}=0.76, \mathrm{DF}=1, P=0.38$; He: $X^{2}=0.10, \mathrm{DF}=1, P=0.75$; Fis: $X^{2}=0.99, \mathrm{DF}=1, P=0.75$ ). In respect to the SC species group, $C$. filicaulis spp. Iuxurians showed the highest allele number and observed heterozygosity, and $C$. dentata showed the highest homozygosity, but the lowest Fis value. $C$. glandulosa showed the largest Fis values of the group (Table 2). On the contrary, $C$. latifolia was the species with the lowest allele number and observed and expected heterozygosity (Table 2). For the SI species, $C$. polifolia was the one with the highest number of alleles per locus and expected heterozygosity, while $C$. dentata showed the highest observed heterozygosity values, but the lowest inbreeding index (Fis). The lowest allele number, and expected heterozygosity were estimated for $C$. seghetti (Table 2). Finally, the correlation analysis did 
not reveal any significant correlation between ISI and the genetic parameters (Pearson correlation; Na: $r=$ 0.05, $P=0.85$; Ho: $r=-0.17, P=0.05$; He: $r=-0.19$, $P=0.52$; Fis: $r=0.14, P=0.62$ ).

Table 2. Parameters of genetic diversity estimated for all the Calceolariaspecies under study using nine microsatellites primers. BS: breeding system, SI: self-incompatible, SC: self-compatible. Na: allelic number, Ho: observed heterozygosity, He: expected heterozygosity and FIS: inbreeding index. Values are given as mean \pm standard error.

\begin{tabular}{llcccc}
\hline BS & Species & $\mathrm{Na}$ & $\mathrm{Ho}$ & $\mathrm{He}$ & Fis \\
\hline SI & C. ascendens & $3.44 \pm 0.5$ & $0.30 \pm 0.12$ & $0.53 \pm 0.08$ & $0.49 \pm 0.18$ \\
\hline & C. dentata & $3.33 \pm 0.5$ & $0.32 \pm 0.09$ & $0.42 \pm 0.09$ & $0.32 \pm 0.10$ \\
\hline C. glandulosa & $3.22 \pm 0.6$ & $0.11 \pm 0.04$ & $0.44 \pm 0.08$ & $0.78 \pm 0.05$ \\
\hline C. filicaulis ssp. filicaulis & $3.00 \pm 0.5$ & $0.18 \pm 0.08$ & $0.35 \pm 0.08$ & $0.63 \pm 0.20$ \\
\hline C. purpurea & $3.44 \pm 0.5$ & $0.19 \pm 0.09$ & $0.51 \pm 0.07$ & $0.53 \pm 0.20$ \\
\hline C. polifolia & $3.78 \pm 0.3$ & $0.31 \pm 0.08$ & $0.55 \pm 0.06$ & $0.41 \pm 0.14$ \\
\hline C. segethii & $2.56 \pm 0.4$ & $0.08 \pm 0.06$ & $0.30 \pm 0.08$ & $0.71 \pm 0.14$ \\
\hline Mean \pm SE & $3.25 \pm 0.47$ & $1.64 \pm 0.08$ & $0.44 \pm 0.08$ & $0.55 \pm 1.01$ \\
\hline SC C. arachnoidea & $3.78 \pm 0.8$ & $0.34 \pm 0.13$ & $0.46 \pm 0.09$ & $0.38 \pm 0.24$ \\
C. corymbosa & $5.78 \pm 1.1$ & $0.39 \pm 0.09$ & $0.63 \pm 0.1$ & $0.39 \pm 0.12$ \\
\hline C. lanigera & $5.00 \pm 0.6$ & $0.34 \pm 0.09$ & $0.57 \pm 0.03$ & $0.35 \pm 0.18$ \\
\hline C. latifolia & $1.89 \pm 0.6$ & $0.04 \pm 0.04$ & $0.20 \pm 0.09$ & $0.83 \pm 0.11$ \\
\hline C. petioalaris & $2.56 \pm 0.4$ & $0.13 \pm 0.06$ & $0.35 \pm 0.08$ & $0.56 \pm 0.17$ \\
\hline C. integrifolia & $2.89 \pm 0.4$ & $0.20 \pm 0.05$ & $0.36 \pm 0.08$ & $0.35 \pm 0.12$ \\
\hline C. filicaulis ssp. luxurians & $6.67 \pm 0.9$ & $0.32 \pm 0.08$ & $0.65 \pm 0.06$ & $0.51 \pm 0.09$ \\
\hline Mean \pm SE & $4.08 \pm 0.69$ & $0.25 \pm 0.08$ & $0.46 \pm 0.08$ & $0.48 \pm 1.03$ \\
\hline
\end{tabular}




\section{Discussion}

The aim of this work was to quantify the ecological and genetic consequences of the evolution of selfincompatibility in 14 species of the genus Calceolaria. Specifically, we sought to test whether selfcompatibility was associated with a) a reduction in floral traits important to the attraction and interaction with pollinators, and $b$ ) decreases in genetic diversity and inbreeding. Our self-incompatibility tests indicated that $50 \%$ of the species studied here are self-incompatible. In relation to floral traits, we found that self-incompatible species do not show a reduction in the size of their floral traits. Finally, our microsatellite analysis did not identify any significant decrease in the genetic diversity or increase in inbreeding levels in the self-compatible Calceolaria species.

\section{Selfing and floral characters}

Floral characters that are directly related to pollinator attraction and pollen transfer are assumed to be under strong selection by pollination agents (see review [21]). This is expected to be even more strongly so in specialized pollination interactions, where the pollinator diversity is relatively low, and thus plant reproduction relies only on a reduced number of potential pollinators. In such cases, it could be expected that fluctuations or lack of pollinators could lead to the evolution of self-compatibility as a way to assure reproductive success. Our results showed that the studied plants use different reproductive strategies, with half of the evaluated species able to produce an equivalent amount of seeds by selfing and outcrossing, and others identified as strict outcrossers.

Even though floral specialization is expected to promote high levels of outcrossing, many plant species with highly specialized pollination systems have the capacity for autonomous selfing [12-14]. Therefore, and considering the level of pollinator specialization in the study system [19, 22-23], it is not surprising that some of the studied species are able to self-pollinate at some level. Further, recent studies in a few Calceolaria species have reveled their capacity for geitonogamy, suggesting an opportunity for the evolution of reproductive assurance mechanisms in the genus [18, 20,24]. Unfortunately, our experiments did not allow us to identify the timing of selfing (i.e., early or delayed), but preliminary trials performed in two species of the genus (i.e., $C$. latifolia and $C$. tripartita) showed that both species are able to selffertilize only at the end of anthesis (i.e., delayed selfing). This is a point that should be further investigated in future works, because it can provide important information on the evolution of the plant- 
pollinator interaction in the system, and on the (in)ability of the pollinators to affect the plant's fitness, and thus its response to specific selective agents (e.g., pollinator identity, presence/absence of pollinators, etc.).

Because a relationship between self-compatibility and pollinator attraction has been proposed and then identified in some systems (see in [11]), our expectation was that floral traits associated with attraction and pollen transfer were also going to be affected by the transition from outcrossing to selfing, and that this relationship was going to involve reduction of the traits with increases in the ability to self. Even though our results indicate a relationship between these traits, this relationship was opposite to that initially expected. In fact, even though ISI values were significantly correlated to morphological traits (i.e., corolla and elaiophore size, herkogamy), the correlation indicated that low ISI values (selfers) were associated with larger trait values. Although this result goes against our expectations it could be explained by the pollinator environment surrounding these species. It is known that according to the degree of unreliability of the pollinator environment, different modes of autonomous selfing may be favored [15], which seems to be especially important in highly specialized pollination systems where mating events are scarce [14]. In such cases, it would be expected for plants to evolve showier flowers that may be more visible and attractive to the few pollinators that may be available in the environment. In such a scenario, one would expect the evolution of delayed selfing and the retention of floral attraction traits, which would still allow outcrossing when the rare pollinators visit the flowers. This would also agree with some studies showing that delayed selfers have higher herkogamy and may not experience a reduction of flower size or display [25-26]. Even though our experimental design is appropriate for characterizing the overall reproductive strategy of the species, it does not allow us to determine the timing of selfing. On this, preliminary tests indicate that the mechanism could be present in at least some Calceolaria species, and this should be the focus of future research in the group.

\section{Is selfing associated with lower genetic diversity in the genus Calceolaria?}

The transition from outcrossing to selfing has happened several times during the evolution of angiosperms. Further, it has been shown that under certain circumstances selfing leads to reduced genetic diversity in populations, especially when selfing is instantaneous and early, and thus competes with outcrossing [27]. In this work we evaluated the genetic diversity of 14 plant species of the genus Calceolaria and evaluated whether their genetic diversity was correlated with different levels of selfincompatibility. Our results indicate that there is not such relationship in the groups, and that all evaluated plants have similar levels of genetic diversity. This result can be explained in different ways. First, it has been shown that under certain conditions (i.e., low inbreeding depression), selfing can evolve in a population and can invade it, becoming an Evolutionary Stable Strategy (ESS) [28-29]. In such a situation, selfers are expected to display low inbreeding depression because those conditions would allow such a strategy to evolve and persist. Second, and related to the first point, we are here comparing data obtained from different species and that we collected at one locality per species only. Based on this, it is possible that the lack of signal is due to the fact that the reproductive strategy is stable at the level we are testing, and that the result would differ if the sampling was to be expanded at the intra-specific 
level (e.g., several populations per species, which experience different pollinator abundance environments). This is a work that should be done in future research.

\section{Conclusions}

To conclude, we did not observe a reduction of floral attraction traits in self-compatible Calceolaria species, but rather found larger corolla, elaiophore area, and herkogamy than of self-incompatible species. Also, we did not find a reduction of genetic diversity or increment in inbreeding levels in selfing species in comparison to outcrossers. Even though this goes against our expectations, it also agrees with previous works. Indeed, it has been observed that specialized plant species maintain mixed breeding systems to affront unsteadiness of pollinator environment. In the case of Calceolaria, their high dependence on only two genera of oil-bees put the species in a vulnerable position, probably facilitating the evolution of mechanisms of reproductive assurance in the absence of pollinators. As a result, the plants maintain their attraction traits while evolving an ability to self.

We did not detect a significant change in genetic diversity or inbreeding when different reproductive strategies are used. This suggests that selfing could be delayed, facilitating -when possible- the exchange of genes by cross-pollination first, and buffering the negative genetic effects of self-pollination. Future studies must further investigate this, what would allow to completely disentangle the main drivers of the evolution of breeding systems in Calceolaria.

\section{Methods}

\section{Breeding system characterization - manual pollination}

In order to determine the breeding system of the 14 Calceolaria species studied here (Table 1: Fig. 1A) a hand-pollination experiment was performed in greenhouse and field conditions. Seeds recollection was carried out by the authors during the 2014-15 springer-summer campaigns, at different unprotected sites throughout the country. Likewise, the field work was realized in populations that inhabit in unprotected areas, for which no government permits are required. Species identification was carried out following the review and description of Chilean species published in the Calceolaria genus monograph [17]. In this occasion, no herbarium material was deposited in any national repository.

In the greenhouse, four species were grown from seeds collected in the field in previous seasons. A total of 1500 seeds per species (thirty seeds per capsule per species) where chosen, sown and germinated in fifty pots, and then grown under daily watering and constant temperature $\left(18^{\circ} \mathrm{C}\right)$. After germination, plants were transplanted into individual 1L-pots and grown until flowering. In the field and during the summer seasons 2016-2018, thirty plants per species (ten species) were selected and covered with a mesh at bud state. Then, both in the greenhouse and the field, six buds per plant were chosen and one of the following treatments was assigned randomly to two of those flowers a) hand self-pollination (HS), emasculated flowers were pollinated using their own pollen; b) hand cross-pollination (HC), emasculated 
flowers were pollinated with pollen of a plant donor situated at least 1 meter apart (in the field) or from plants grown from different seed capsules (in the greenhouse). After performing the treatments, the flower was kept isolated from further pollination with the mesh bag, and the flowers were left to develop until fructification. For each species, we quantified pollination success as in [30], using seed-set per plant to calculate an average self-incompatibility index (ISI) where, the seed-set values are the average number of seeds per fruit per treatment (ISI=HS/HC). ISI index ranges from 0 to 1 , where species that present values close to zero are considered self-incompatible, while when the index values tend to one the species is considered to harbor a greater degree of self-compatibility. In our case, species where at most $20 \%$ of the seeds could be produced by self-pollination (ISI $\leq 0.2$ ) were considered as self-incompatible (SI), while the remainders were considered as self-compatible (SC) [31].

\section{Floral traits measurements}

Thirty to 100 flowers per species were chosen for floral trait measurements. To do this, each flower was photographed from a frontal view with a camera Sony and three floral traits were measured from pictures using ImageJ 1.46r (http://rsb.info.nih.gov/ij/, Fig. 1B). We chose floral traits based on their importance for pollinator attraction (corolla area, CA; elaiophore area, EA) and the effect on the mechanical ability of the plant to self-pollinate (herkogamy, $\mathrm{H}$ ).

In order to reduce the dimensionality and avoid correlation among floral traits, a principal component analysis (PCA) was performed on log-modified measurements, and the scores of the two principal components were used in the posterior statistical analysis. To test for potential differences in floral morphology (i.e, PCA scores) between species with different ISIs, we adjusted GLMs using a Gaussian distribution in R [32]; analyses with the raw traits are presented in the Supplementary Information). Here, our expectation was that ISI was positively and significantly explained by trait measures.

\section{DNA extraction and genotyping}

Three leaves per plant were collected and preserved in silica gel (a total of 420 individuals across the 14 species) either from field- or greenhouse-grown plants. DNA extractions were done on $\sim 20 \mathrm{mg}$ of dry material using a modified cetyltrimethyl ammonium bromide (CTAB) protocol [33]. Fifteen microsatellites previously described by [34] were tested on three samples per species. The PCR mix (10ul) was composed of: 10x PCR buffer, $5 \mathrm{mM} \mathrm{MgCl} 2,2.5 \mathrm{mM}$ dNTP (Invitrogen), $5 \mathrm{mM}$ forward primer, $5 \mathrm{mM}$ reverse primer, $5 \mathrm{mM}$ fluorescently labeled M13 universal primer, 1U GoTaq G2 (Invitrogen, Thermo Fisher Scientific, Waltham, MA, USA), $1 \mu \mathrm{L}$ BSA, $20 \mathrm{ng} / \mathrm{ul}$ template DNA and $\mathrm{H}_{2} \mathrm{O}$. PCR cycling conditions were set as follows: 5 minutes of denaturation at $95^{\circ} \mathrm{C}$, followed by 30 cycles of 1 minute at $95^{\circ} \mathrm{C}, 1$ minute of annealing at $58^{\circ} \mathrm{C}, 1$-minute extension at $72^{\circ} \mathrm{C}$ and 10 minutes of final extension at $72^{\circ} \mathrm{C}$. Only those primers that showed amplification (9/15; see Results) were genotyped on ten individuals per species. PCR 
products were genotyped on a 3130xl Genetic Analyzer (Applied Biosystems, Life Technologies, ThermoFisher Scientific, Waltham, MA, USA) at the Pontificia Universidad Católica de Chile.

We analyzed all genotypes using GeneMapper v.5 (Applied Biosystems). We checked for null alleles using Microchecker v.2.2.3 [35]. We tested for departures from Hardy-Weinberg equilibrium (HWE) using GenAlEx 6.5 [36]. We quantified genetic variation using several genetic measures: the number of alleles per locus $(\mathrm{Na})$, observed $(\mathrm{Ho})$ and expected $(\mathrm{He})$ heterozygosity, and the fixation index $F_{I S}$. Here, our expectation is that SC species will display significantly larger genetic diversity than SI species. In order to determine statistical differences in the genetic diversity parameters between SI and SC species, we ran a Kruskal-Wallis test in $\mathrm{R}$ [32] between values for the two groups. Finally, to determine a relationship between the level of self-incompatibility and the genetic diversity of the species, we calculated a Pearson correlation between ISI values and each genetic parameter, in R.

\section{Abbreviations}

BS: breeding system; CA: corolla area; EA: corolla elaiophore; FIS: inbreeding index; H: herkogamy; Ho: observed heterozygosity; He: expected heterozygosity; ISI: self-incompatible index; LF: loading factor; Na: allelic number; PCA: principal component analysis; SI: self-incompatible; SC: self-compatible.

\section{Declarations}

\section{Acknowledgments}

The authors thanks to Pontificia Universidad Católica de Chile for greenhouse and laboratory facilitation. The authors also thanks to Isidora Sepulveda, Carmen Gloria Ossa and Javiera Chinga for field collaboration.

\section{Author's Contribution}

$\mathrm{MM}$ and FP conceived and designed the experiments. MM executed the reproductive experiments and performed the molecular procedures. $\mathrm{MM}$ and $\mathrm{AE}$ analyzed the data. $\mathrm{MM}, \mathrm{AE}$ and FP wrote the manuscript. All authors have read and approved the manuscript.

\section{Funding}

All the laboratory labors, as well as, the cost of the fieldwork campaign, were entirely founded by Fondecyt PD3150267, 11170377 (MM) and Fondecyt 1141047 (FP), Conicyt.

\section{Availability of data and materials}


The datasets used in current study are available from the corresponding author as request.

\section{Ethics approval and consent to participate}

No applicable for this study.

\section{Consent for publication}

No applicable for this study.

\section{Competing interests}

The authors declare that they do not have competing interests.

\section{References}

1. Stebbins GL. Flowering plants: evolution above the species level. Harvard University Press, Cambridge; 1974.

2. Takebayashi N, Morrell PL. Is self-fertilization an evolutionary dead end? Revisiting an old hypothesis with genetic theories and a macroevolutionary approach. Am J Bot. 2001;88: 1143-1150.

3. Wright SI, Kalisz S, Slotte T. Evolutionary consequences of self-fertilization in plants. Proc R Soc B Sci 2013;280: 20130133.

4. Cruden RW. Pollen-ovule ratios: a conservative indicator of breeding systems in plants. Evolution 1977;31:32-46.

5. Bodbyl SA, Kelly JK. Rapid evolution caused by pollinator loss in Mimulus guttatus. Evolution. 2011; 65: 2541-2552.

6. Brunet J. Effects of floral morphology and display on outcrossing in Blue Columbine, Aquilegia caerulea (Ranunculaceae). Func Ecol. 2002; 12: 596 - 606.

7. Sicard A, Lenhard M. The selfing syndrome: a model for studying the genetic and evolutionary basis of morphological adaptation in plants. Ann. Bot. 2011;107: 1433-1443.

8. Kalisz S, Vogler DW. Benefits of autonomous selfing under unpredictable pollinator environments. Ecology 2003;84: 2928-2942.

9. Brys R, Geens B, Beeckman T, Jacquemyn H. Differences in dichogamy and herkogamy contribute to higher selfing in contrasting environments in the annual Blackstonia perfoliata (Gentianaceae). Ann 
Bot. 2013; 111: 651-661.

10. Lande R, Schemske DW. The evolution of self-fertilization and inbreeding depression in plants. I. Genetic models. Evolution. 1985;39: 24-40.

11. Goodwillie C, Sargent RD, Eckert CG, Elle E, Geber MA, Johnston MO, Kalisz S, Moeller DA, Ree $\mathrm{RH}$, Vallejo-Marin M, Winn AA. Correlated evolution of mating system and floral display traits in flowering plants and its implications for the distribution of mating system variation. New Phyt.2010;185: 311-321.

12. Pérez F, Arroyo MTK, Armesto JJ. Evolution of autonomous selfing accompanies increased specialization in the pollination system of Schizanthus (Solanaceae). Am. J. Bot. 2009; 96: 11681176.

13. Zhang L, Barrett S, Gao J-Y, Chen J, Cole WW, Yong L, Bai Z-L, Li Q-J. Predicting mating patterns from pollination syndromes: the case of "sapromyiophily" in Tacca chantrieri (Taccaceae). Am J Bot 2015; 92: 517-524.

14. Fenster CB, Marten-Rodriguez S. Reproductive assurance and the evolution of pollination specialization, Int. J. Plant Sci. 2017; 168: 215-228.

15. Lloyd DG, Schoen DJ. Self- and cross-fertilization in plants. I. Functional dimensions. Int. J. Plant Sci. 1992;153: 358-369.

16. Molau U. Scrophulariaceae-Part I. Calceolarieae. Flora Netrop. 1988; 47: 1-326.

17. Ehrhart C. Die Gattung Calceolaria (Scrophulariaceae) in Chile. Biblioth. Bot. 2000;153: 1-283.

18. Sérsic A. Pollination Biology in the Genus Calceolaria L.(Calceolariaceae). Stapfia. 2004;82:1-121.

19. Cosacov A, Sérsic AN, Sosa V, De-Nova JA, Nylinder S, Cocucci A. New insights into the phylogenetic relationships, character evolution, and phytogeographic patterns of Calceolaria (Calceolariaceae). Am. J. Bot. 2009; 96:2240-2255.

20. Cisterna J, Murúa M. Contrasting floral morphology and breeding systems in two subspecies of Calceolaria corymbosa in Central Chile. Gayana Bot. 2018; 75:544-548.

21. Harder LD, Johnson SD. Darwin's beautiful contrivances: evolutionary and functional evidence for floral adaptation. New Phytol. 2009;183: 530-545.

22. Cosacov A, Cocucci AA, Sersic AN. Geographic differentiation in floral traits across the distribution range of the Patagonian oil-secreting Calceolaria polyrhiza: do pollinators mater? Ann. Bot. 2014;113: 251-266.

23. Murúa M, Espíndola A. Pollination syndromes in a specialized plant-pollinator interaction: Does floral morphology predict pollinators in Calceolaria? Plant Biol. 2015; 17: 551-7.

24. Murúa M, Cisterna J, Rosende B. Pollination ecology and breeding system of two Calceolaria species in Chile. Rev. Chil. Hist. Nat. 2014;87: 7.

25. Armbruster WS, Mulder CP, Baldwin BG, Kalisz S, Wessa B, Nute H. Comparative analysis of late floral development and mating-system evolution in tribe Collinsieae (Scrophulariaceae sl). Am. J. Bot. 2002;89: 37-49. 
26. Kalisz S, Randle A, Chaiffetz D, Faigeles M, Butera M, Beight C. Dichogamy correlates with outcrossing rate and defines the selfing syndrome in the mixed-mating genus Collinsia. Ann Bot. 2012; 109: 571-82.

27. Herlihy CR, Eckert CG. Genetic cost of reproductive assurance in a self-fertilizing plant. Nature. 2002; 416:6878.

28. Husband BC, Schemske DW (1996) Evolution of the magnitude and timing of inbreeding depression in plants. Evolution. 1996; 50: 54-70.

29. de Jong TJ, Klinkhammer PGL. Evolutionary ecology of plant reproductive strategies. Cambridge University Press, Cambridge, UK. 2005.

30. Ruiz T, Arroyo MTK. Plant reproductive ecology of a secondary deciduous forest in Venezuela. Biotropica. 1978;10: 221-230.

31. Bawa KS. Patterns of flowering in tropical plants. In: C.E. Jones \& R.J. Little (eds.), Handbook of experimental pollination biology. Van Nostrand Reinhold, New York, USA; 1983. p. 394-410.

32. Core Team 2019. R: A language and environment for statistical computing.

33. Doyle JJ, Doyle JL. A rapid DNA isolation procedure for small quantities of fresh leaf tissue. Phytochem Bull. 1987;19: 11-15.

34. Murúa M, Peralta G, Carrasco L, Pérez F. Isolation and cross-amplification of fifteen microsatellites for oil-rewarding Calceolaria species (Calceolariaceae). Genet Mol Res. 2018; 17: gmr16039863.

35. van Oosterhout C, Hutchinson WF, Shipley P. Micro-checker: software for identifying and correcting genotyping errors in microsatellite data. 2004;4: 535-338.

36. Peakall R, Smouse PE. GenAIEx 6.5: genetic analysis in Excel. Population genetic software for teaching and research-an update. Bioinformatics. 2012; 28: 2537-2539.

\section{Figures}



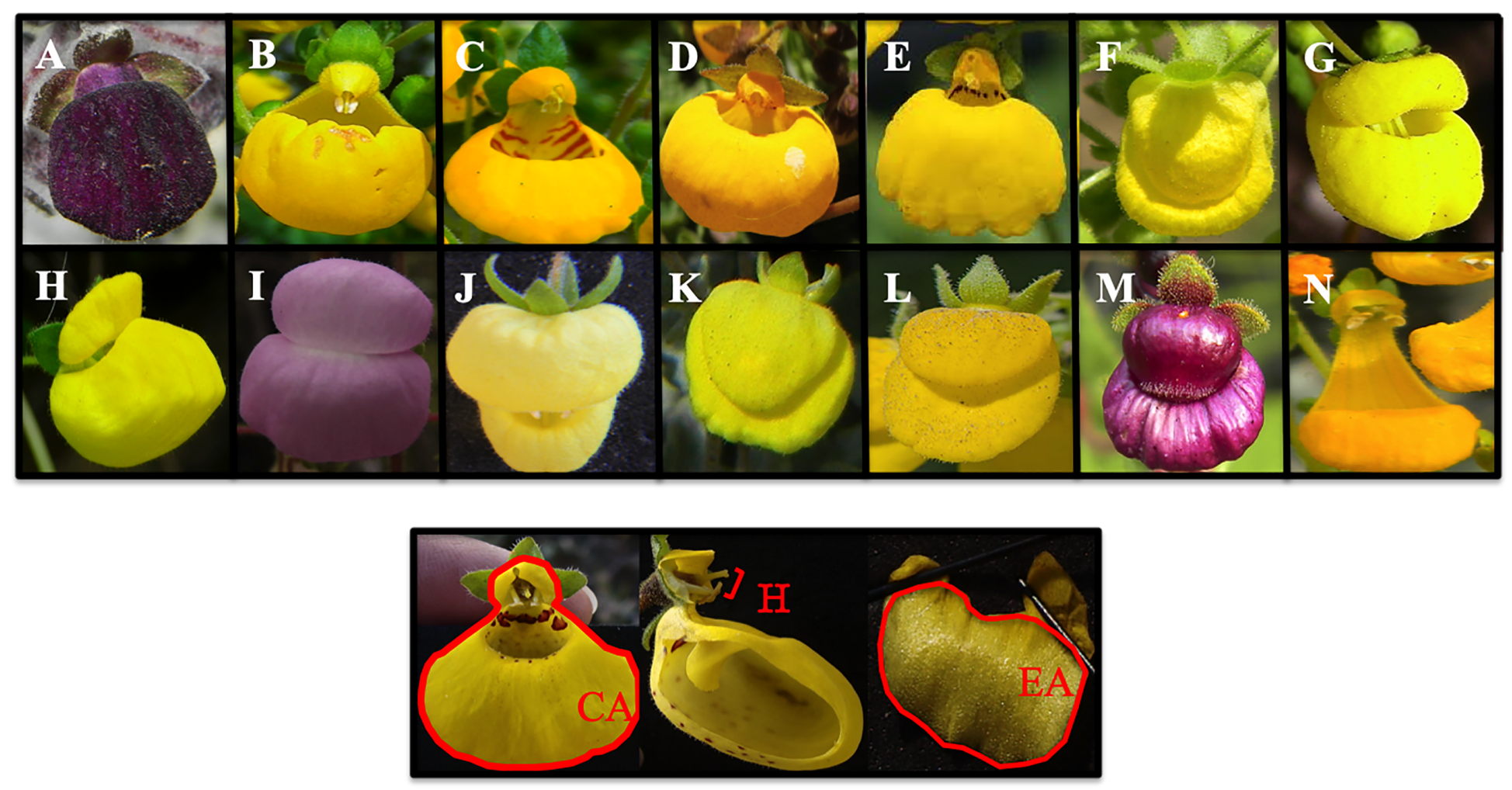

\section{Figure 1}

Fourteen species of Calceolaria genus under study. a) C. arachnoidea, b) C. ascendens, c) C. corymbosa, d) C. filicaulis var. luxurians, e) C. filicaulis, f) C. dentata, g) C. integrifolia, h) C. glandulosa, i) C. lanigera, j) C. Iatifolia, k) C. petiolaris, I) C. polifolia, m) C. purpurea, and n) C. segethii. Details of floral traits measurements are depicted in red as follow: $\mathrm{CA}$ : corolla area, $\mathrm{H}$ : hercogamy and EA: elaiophore area.
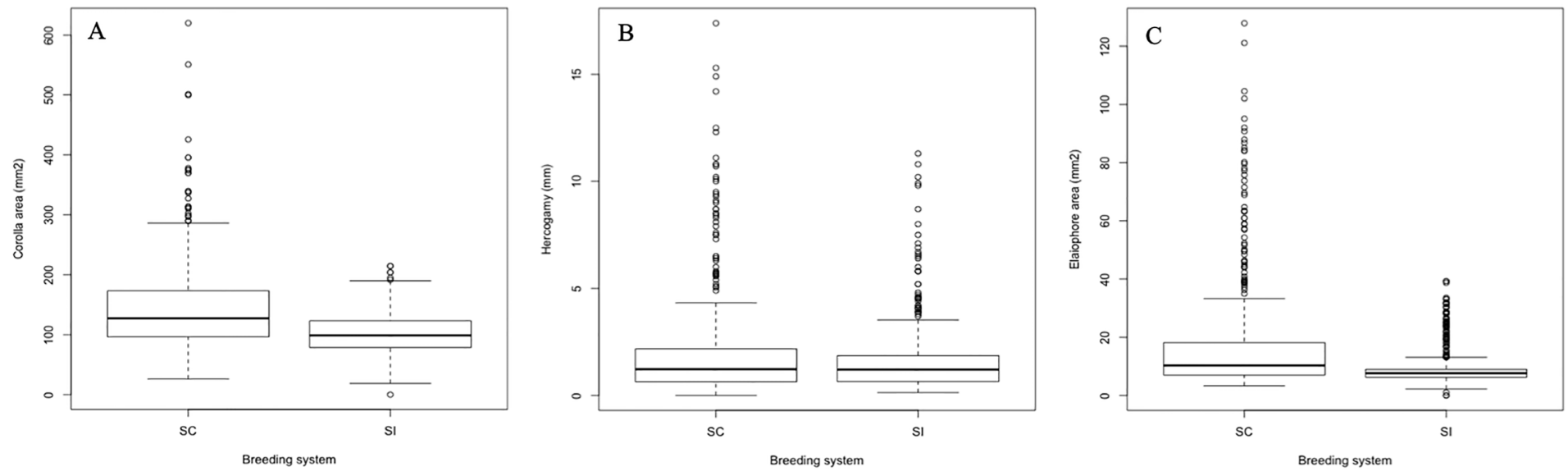

Figure 2

Box plot of the three floral traits measurements for each breeding system. A) Corolla area, B) Hercogamy, and C) Elaiophore. SI: self-incompatibility and SC: self-compatibility. 


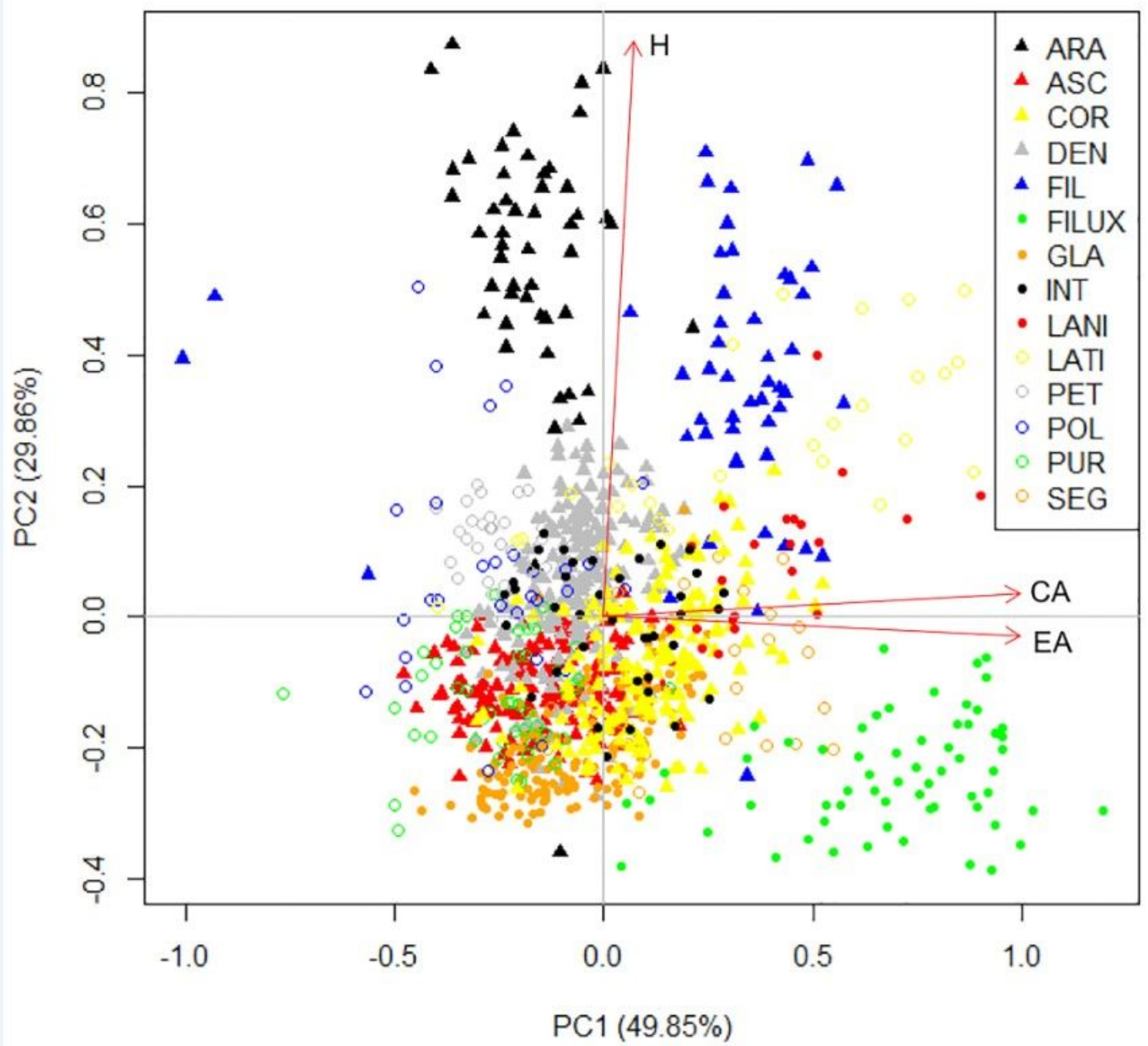

Figure 3

Principal components analysis (PCA) for the three floral traits measured in the Calceolaria species. PCA vectors for the first and the second PCA axes are revealed. Percentage of explained variance is shown on the axes. Floral traits: CA: corolla area, $\mathrm{H}$ : hercogamy and EA: elaiophore area. Calceolaria species: ARA: C. arachnoidea, ASC: C. ascendens, COR: C. corymbosa, DEN: C. dentata, FIL: C. filicaulis, FILUX: C. filicaulis var.luxurians, GLA: C. glandulosa, INT: C. integrifolia, LANI: C. lanigera, LATI: C. latifolia, PET: C. petiolaris, POL: C. polifolia, PUR: C. purpurea, and SEG: C. segethii. 


\section{Supplementary Files}

This is a list of supplementary files associated with this preprint. Click to download.

- AdditionalFile1.docx 